ZENON GAJDZICA

Uniwersytet Śląsi

w Katowicach

\title{
KULTURA ORGANIZACYJNA SZKOŁY INTEGRACYJNEJ W ZWIERCIADLE KULTURY POGRANICZA
}

ABSTRACT. Gajdzica Zenon, Kultura organizacyjna szkoty integracyjnej w zwierciadle kultury pogranicza [Organizational Culture of Integrated School in the Mirror of Borderland Culture]. Studia Edukacyjne nr 42, 2016, Poznań 2016, pp. 85-95. Adam Mickiewicz University Press. ISSN 1233-6688. DOI: $10.14746 /$ se.2016.42.5

The thesis is put forward in the presented article that the organizational specificity of integrated education creates a unique culture with some characteristics of typical borderland. Integrated school is a place where the dominating and the subordinated culture clash and/or collaborate. Depending on the precisely specified assumptions, beliefs, the recognized values and norms (consolidated within the institutional knowledge of a particular school), two different cultures of integrated school can be formed. These cultures are shaped by two types of social practices and two different models of the functioning of school. The study is aimed at a preliminary attempt to specify these models. They are assumed to comprise a set of notions which constitute analytical categories useful in describing the daily routine of school. Moreover, these models may become a tool for interpreting and understanding the states, processes and features of some elements of school and their interrelations.

Key words: culture, organizational culture of school, integrated school, disability, special educational needs, borderland

\section{Wprowadzenie}

Kultura jest społecznie akceptowaną (lub przynajmniej respektowaną) wiedzą określonej grupy ludzi, jest utrwalana i przekazywana w jej obrębie, ponadto sprawia, że dany system społeczno-kulturowy funkcjonuje jako współzależna całość, zachowuje stabilność oraz zdolność odtwarzania. Na kulturę zatem składa się między innymi wszystko co trzeba wiedzieć, czy też to w co trzeba wierzyć, aby postępować w sposób akceptowalny¹. Ana-

${ }^{1}$ W.J. Burszta, Antropologia kultury. Tematy, teorie, interpretacje, Poznań 1998, s. 49. 
logicznie jest z kulturą szkoły. Przyjmując, że stanowi ją ogół przekonań, poglądów, postaw, relacji, zasad kształtujących wszystkie aspekty funkcjonowania szkoły jako instytucji, organizacji i wspólnoty ${ }^{2}$ - podstawą jej podtrzymywania i współkreowania jest wiedza o nich. Każda szkoła tworzy mikroklimat, który jest pochodną stosunków społecznych, relacji, postaw oraz norm i zasad je kształtujących. Jest on wypadkową czynników zewnętrznych oraz wewnętrznych ${ }^{3}$.

W artykule stawiam tezę, że specyfika organizacyjna kształcenia integracyjnego tworzy unikatową kulturę noszącą znamiona typowego pogranicza. Szkoła integracyjna to przestrzeń zderzenia się i/lub współpracy kultury dominującej i podporządkowanej. W zależności od sprecyzowanych założeń, przekonań, uznawanych wartości i norm - ugruntowanych na wiedzy instytucjonalnej konkretnej placówki - mogą tworzyć się dwie różne kultury szkoły integracyjnej. Te zaś kształtują dwa typy praktyk społecznych i dwa rożne modele funkcjonowania szkoły. Próba wstępnego nakreślenia tych modeli stanowi cel opracowania. W założeniach zawierają one zbiór pojęć stanowiących kategorie analityczne przydatne w deskrypcji codzienności szkoły. Ponadto, mogą one stanowić narzędzie służące interpretowaniu i rozumieniu stanów, procesów, własności elementów szkoły oraz ich powiązań.

\section{Kultura organizacyjna szkoły}

Kultura jako wytwór człowieka kształtuje zarówno ludzki umysł, jak i warunkuje jego funkcjonowanie. Zgodnie $z$ tym poglądem myślenie i uczenie się zawsze sytuują się $\mathrm{w}$ środowisku kulturowym, ponadto są zależne od stopnia wykorzystania jego zasobów ${ }^{4}$. Kultura jest więc w pewnym zakresie czynnikiem "programującym” mentalnie umysł. Uczymy się jej w różnych środowiskach. Pierwszym i zarazem prymarnym jest rodzinna. Kolejnym szkoła, a następnymi inne środowiska życia człowieka (grupa rówieśnicza, środowisko pracy itp.). Zaprogramowanie kulturowe jest czę-

2 Za: M. Czerepaniak-Walczak, Kultura szkoty - o jej złożoności i wielowymiarowości, Pedagogika Społeczna, 2015, 3(57), s. 80.

3 U J. Hofstede czynniki zewnętrzne ulokowane są na poziomie kultury narodowej; związanej z przynależnością do grupy regionalnej, etnicznej, językowej, religijnej; związanej z przynależnością do płci; kultury pokoleniowej; społecznej związanej m.in. z wykształceniem, natomiast wewnętrzne - na poziomie kultury organizacyjnej lub korporacyjnej związanej $\mathrm{z}$ rolą i stanowiskiem w miejscu pracy. Zob. J. Hofstede, Kultura i organizacje. Zaprogramowanie umystu, Warszawa 2000.

4 J. Bruner, Kultura edukacji, Kraków 2010, s. 16. 
ściowym determinantem zachowania osoby, możliwe są odstępstwa wyrażające się w zachowaniach twórczych - zarówno konstruktywnych jak i destruktywnych ${ }^{5}$. Są one, przynajmniej częściowo, wynikiem zderzenia się kultur poszczególnych środowisk. Do jednego z pierwszych zderzeń w życiu człowieka może dochodzić $\mathrm{w}$ relacji kultury rodziny $\mathrm{z}$ kulturą szkoły, ale także zderzania się różnych kultur w obrębie szkoły.

Kultura szkoły jest odzwierciedleniem kultury ją otaczającej. Nie oznacza to jednak, że zawsze musi być w pełni analogiczna wobec jej lokalnych odmian. Jest to szczególnie widoczne $\mathrm{w}$ analizowaniu funkcji dominujących w danej placówce. Jeżeli przyjmiemy, że jej głównym celem jest transmisja i ukształtowanie ucznia do konformistycznego ulokowania się w otaczającej rzeczywistości i utrwalania istniejącego porządku' ${ }^{6}$, kultura szkoły powinna temu sprzyjać wpisując się $\mathrm{w}$ kulturę otoczenia. Jeżeli natomiast celem jest przygotowanie wychowanka do aktywnego, wyemancypowanego działania, a zarazem współkreowania kultury, wówczas kultura szkoły przynajmniej częściowo powinna wykraczać poza jej ramy.

Kultura szkoły jest podtrzymywana i kreowana przez wszystkich uczestników procesów zachodzących w przestrzeni tej placówki, czyli: nauczycieli, uczniów, innych pracowników, a także rodziców, szczególnie tych zaangażowanych w życie szkoły ${ }^{7}$. Prócz tego, nawiązując do ulokowanych zewnętrznie czynników tworzących kulturę szkoły (choć zapewne w mniejszym zakresie), należy przywołać osoby wpływające na życie szkoły, m.in. z nadzoru kuratoryjnego, jednostki samorządu terytorialnego, instytucji i organizacji współpracujących ze szkołą. Osoby te w bezpośredni lub pośredni, formalny i nieformalny sposób mogą kulturę tę kształtować i bardziej lub mniej świadomie podtrzymywać niektóre jej wymiary - zwłaszcza $\mathrm{w}$ zakresie organizacyjnym.

Do popularnych - zapewne także ze względu na przejrzystość - należą koncepcje kultury organizacyjnej szkoły. Część z nich została zaczerpnięta z nauk o zarządzaniu, gdzie problematyka kultury organizacji i kultury $\mathrm{w}$ organizacji ma dłuższą tradycję badawczą ${ }^{8}$. Przykładem jest koncepcja Edgara Scheina9, który opracował sposób diagnozowania organizacji na podstawie elementów kultury określając je mianem poziomów. Założył on,

${ }^{5}$ G. Hofstede, G.J. Hofstede, M. Minkov, Kultury i organizacje, Warszawa 2011, s. 20.

${ }^{6}$ Nieco upraszczając, jako przykład mogą służyć społeczne funkcje szkoły: kwalifikacyjna, selekcji i integracji. Zob.: F.W. Kron, Pedagogika. Kluczowe zagadnienia. Pojęcia, procesy, modele, przekł. E. Cieślik, Sopot 2012, s. 237-240.

${ }^{7}$ M. Czerepaniak-Walczak, Kultura, s. 80.

8 Por. M. Kostera, Antropologia organizacji. Metodologia badań terenowych, Warszawa 2003, s. 29-38.

${ }_{9}^{9}$ E. Schein, Organization Culture and Leadership, San Francisco 1992. 
że kultura organizacji jest zbiorem złożonych czynników, na które można wywierać wpływ, jeżeli podda się ją trafnej diagnozie ${ }^{10}$. Wyróżnił on trzy podstawowe poziomy kultury organizacji: artefaktów, uznanych wartości i podstawowych założeń ${ }^{11}$. Artefakty są tym, co odbiera się przez zmysły i czuje, gdy styka się z nową grupą o nieznanej kulturze. Składają się one na obraz danej kultury i ujawniają, czym ona jest dla członków grupy. Obejmują wyroby, usługi, a nawet wzory zachowań członków organizacji12. Uznawane wartości to podawane przez organizację powody, dla których postępuje się $\mathrm{w}$ określony sposób, a podstawowe założenia to przekonania przyjmowane bezkrytycznie przez członków organizacji13.

Koncepcja ta stała się podstawą modelu kultury organizacji szkoły autorstwa Davida Tuohy'ego, który wyróżnia trzy analogiczne poziomy organizacyjnej kultury szkoły ${ }^{14}$.

- Wytwory obejmują rytuały, role i normy. Są uzewnętrznionymi działaniami podejmowanymi w przestrzeni szkoły - opisują co robi organizacja. Rytuały szkolne konstytuują się w związku z harmonogramami zajęć. Są celebrowanymi zwyczajami, sposobami komunikowania się (np. sposoby witania się, honorowania osiągnięć). Role to formalnie wyrażone reguły. Precyzują prawa i obowiązki osób stanowiących społeczność szkolną (dyrektora, administracji, nauczycieli, uczniów i rodziców). Normy to uzewnętrznione nakazy moralne nakładane na członków społeczności szkolnej. Przekroczenie norm powoduje uruchomienie sankcji, które zależne są także od roli (pozycji) w społeczności szkolnej. Wytwory kultury szkoły są łatwo zauważalne, jednak trudno je zinterpretować.

- Wartości to pożądane stany rzeczy stanowiące uporządkowaną hierarchię. Ukierunkowują one działania nauczycieli i uczniów (zapewne także innych pracowników szkoły). Wpływają więc na wybór celów oraz środków służących ich realizacji. $W$ organizacjach, a więc także $w$ szkole, mogą być jawne (deklarowane - głoszone przez szkołę) i ukryte. Część z nich jest uznawana powszechnie i lokowana centralnie (np. pilna nauka), inne podzielane są przez część społeczności i umieszczane w przestrzeniach peryferyjnych, traktowanych wybiórczo (np. uczestnictwo w zajęciach pozalekcyjnych).

${ }^{10}$ M. Kostera, Antropologia organizacji, s. 31.

11 Za: J.A.F. Stoner, R.E. Freeman, D.R. Gilbert, Kierowanie, przekł. A. Erlich, Warszawa 2001, s. 190.

$12 \mathrm{~W}$ odniesieniu do szkoły integracyjnej elementem takim może być swoisty folklor szkolny. Zob. M. Bełza, Inny/Obcy (uczeń niepetnosprawny) jako podmiot "folkloru" szkolnego, Problemy Edukacji, Rehabilitacji i Socjalizacji Osób Niepełnosprawnych, 2016, 23.

13 Tamże, s. 190-192.

14 D. Tuohy, Dusza szkoły. O tym, co sprzyja zmianie i rozwojowi, przekł. K. Kruszewski, Warszawa 2002, s. 25-26. 
- Założenia dotyczą idei i przekonań leżących u podstaw organizacji szkoły - jej zadań i właściwej organizacji. Opierają się na uznanych koncepcjach dotyczących kształcenia i oświaty, historii i prestiżu danej szkoły oraz potocznym poglądzie celów, jakie powinna realizować. Tworzą zatem pewnego rodzaju ideologiczny fundament szkoły. Nadają codziennym zdarzeniom w szkole określone znaczenie ${ }^{15}$.

Założenia te dotyczą:

- związków szkoły z otoczeniem - określają jej obraz, misję, powiązania $\mathrm{z}$ innymi instytucjami (ze światem zewnętrznym), ukazują granice (precyzując sposób ich wytyczania, a zarazem jej hermetyczność i zależność od otoczenia);

- natury ludzkich działań - ukazują wizję celów szkoły w określonej perspektywie (np. przyjęcie perspektywy bierności służy celom reprodukcji i przystosowaniu versus przyjęcie perspektywy aktywności prowadzi do wyrabiania krytycznego stosunku wobec otaczającej rzeczywistości). W praktyce obie perspektywy mieszczą się $\mathrm{w}$ jednej kulturze, która odzwierciedla napięcia i równowagę między nimi, założenia te warunkują zatem wizję człowieka i grupują cele, a w rezultacie także metody pracy;

- prawdy i czasu - precyzują perspektywy zorientowania na obiektywność versus subiektywność, orientację na przeszłość, teraźniejszość lub przyszłość, kreują zatem część kryteriów pracy szkoły;

- natury ludzkiej - precyzują postawy wobec uczniów, ukazują przekonania na temat stałości i podatności na zmiany;

- związków między ludźmi - obejmują założenia życia społecznego, dystrybucji władzy i statusu, wpływają zatem na stosunki między nauczycielami, uczniami, rodzicami, pracownikami administracji, ustalają więzi między nimi i hierarchię władzy oraz pozycje, definiują role. Relacje te przekładają się m.in. na podejście do zróżnicowania i ujednolicenia. Służą wypracowaniu rozdziału środków ${ }^{16}$.

Mariola Chomczyńska-Rubacha podejmując próbę przełożenia przywołanej koncepcji na kategorie adekwatne dla opisu kultury szkoły, proponuje przyjąć założenia o: związkach szkoły z otoczeniem, związkach między ludźmi, naturze uczniów i ich aktywności, wiedzy17.

Wymienione trzy poziomy różnią się możliwością ich bezpośredniego zaobserwowania. Dostrzegalne to te, które dotyczą wytworów w postaci

15 Tamże, s. 27.

16 Tamże, s. 27-36. Syntezę tych założeń prezentuje B. Adrjan, Kultura szkoty. W poszukiwaniu nieuchwytnego, Kraków 2011, s. 57.

${ }_{17}$ M. Chomczyńska-Rubacha, Szkolne środowisko uczenia się, [w:] Pedagogika, t. 2, red. Z. Kwieciński, B. Śliwerski, Warszawa 2006, s. 242. 
artefaktów. Trudniej jednoznacznie rozpoznać uznawane wartości, natomiast założenia jako przekonania stanowią poziom najtrudniejszy do zaobserwowania. Nieco inaczej określając, można w modelu tym wyróżnić elementy kultury percepcyjnej (uchwytne) i elementy koncepcyjne (niedające się bezpośrednio uchwycić). Te drugie (wartości, założenia) tworzą intelektualne podstawy wszelkich działań $\mathrm{w}$ organizacji, zatem warunkują elementy percepcyjne (symbole, wzorce zachowań) ${ }^{18}$.

\section{Szkoła integracyjna jako przestrzeń pogranicza}

Model edukacji integracyjnej, powszechnie stosowany w naszym kraju, generuje środowisko o cechach unikatowych. Jego istota zasadza się na kontaminacji złożonych oczekiwań społecznych oraz integracji koncepcji kształcenia zakorzenionego $\mathrm{w}$ tradycji edukacji ogólnodostępnej oraz specjalnej. Nie należy jednak traktować modelu tego jako swoistej hybrydy wysuniętej poza margines normalności systemu szkolnego. Wszak przestrzeń szkoły integracyjnej jest immanentną częścią całego systemu, a uczniowie i nauczyciele podlegają wielu analogicznym regułom wymagań i oczekiwań, jak $\mathrm{w}$ innych formach kształcenia. Trudno jednak zaprzeczyć, że kształcenie integracyjne niesie ze sobą nie tylko praktyczną swoistość, ale również koncepcyjną oryginalność ${ }^{19}$. Wspominając o niej, nie koncentruję się jedynie na samych nietypowych dla innych form warunkach (jak np. zróżnicowane możliwości podmiotów działań, dwaj nauczyciele o różnych kompetencjach i częściowo odmiennych zadaniach), ale przede wszystkim na wytworzonej, szeroko pojętej kulturze. Konstruowana jest ona na ogólnych postawach wobec osób niepełnosprawnych oraz wiedzy potocznej i instytucjonalnej konkretnych placówek ${ }^{20}$. Zakładam, że owa kultura warunkuje powszechnie uznawane wartości i założenia oraz wytworzone na ich kanwie praktyki.

Kultura ta stanowi odzwierciedlenie typowego pogranicza: współistnienia ze sobą $\mathrm{w}$ jednym obszarze rozmaitych regulacji normatywnych, reguł gry, kodów kulturowych itp., ścierania się zróżnicowanych grup, odmiennych kultur, oczekiwań21, co uzasadnia wykorzystanie kategorii pogranicza

${ }_{18}$ A. Wojtowicz, Istota i modele kultury organizacyjnej - przeglad koncepcji, Zeszyty Naukowe Małopolskiej Wyższej Szkoły Ekonomicznej w Tarnowie, 2004, 5, s. 167.

${ }^{19}$ Z. Gajdzica, Kategorie sukcesów w opiniach nauczycieli klas integracyjnych jako przyczynek do poszukiwania koncepcji edukacji integracyjnej, Kraków 2013, s. 238.

20 Z. Gajdzica, Klasa integracyjna jako przystań pograniczy, Teraźniejszość-CzłowiekEdukacja, 2015, 4, s. 117-127.

${ }^{21}$ Zob. np. R. Kantor, Kultura pogranicza jako problem etnograficzny, [w:] Zderzenia i przenikania kultur na pograniczach, red. Z. Jasiński, J. Korbel, Opole 1989, s. 243; G. Babiński, Pogranicze etniczne, pogranicze kulturowe, peryferie. Szkic wstępny problematyki, Pogranicze. Studia Społecz- 
w prowadzonych analizach. Przypomnijmy, że szkoła integracyjna, a w jej obszarze klasa, obejmuje przestrzeń współbycia i współdziałania:

- dwóch nauczycieli o nierzadko odmiennym doświadczeniu;

- uczniów o różnych możliwościach poznawczych, potencjale adaptacyjnym i kreacyjnym, formalnie podzielonych na tych z orzeczeniem o potrzebie kształcenia specjalnego i bez takiego orzeczenia;

- dwóch kultur tradycyjnie osadzonych w edukacji specjalnej oraz ogólnodostępnej.

Istotne dla dalszej części wywodu jest podkreślenie rozbieżności w postrzeganiu niepełnosprawności oraz w związku z nim specjalnych potrzeb (specjalnej drogi realizacji potrzeb) uczniów z niepełnosprawnościami, a w rezultacie również zadań nauczycieli i terapeutów. To zaś wpisuje się w konstrukcję dwóch możliwych typów założeń tworzących fundament kultury szkoły. Metaforycznie wpisują się w dwie formy pogranicza.

- Jedną jest występowanie obok siebie grup i kultur, współwystępowanie odmiennych wartości i tradycji, różnych tożsamości i profili mentalnych. Charakter takiego pogranicza przejawia się między innymi w równoległym funkcjonowaniu dwóch języków w życiu codziennym, specyficznych obyczajach każdej grupy, podtrzymywaniu negatywnych stereotypów narodowościowych, rzutowaniu podziałów wyznaniowych (religijnych) na postawy gospodarcze, polityczne i społeczne.

- Drugą formą jest przenikanie się kultur sąsiadujących. W rezultacie tego tworzy się jakościowa odmiennie całość społeczno-kulturowa pogranicza. To zaś znajduje swoje odbicie w osobliwej tożsamości jego mieszkańców. Przywiązaniu do własnej odrębności, w tych okolicznościach, towarzyszy jednak podzielanie wartości oraz interesów ojczyzny ideologicznej22.

\section{Specyfika kultury szkoły integracyjnej - dwa typy pogranicza}

Zgodnie z przywołaną już wcześniej tezą, podstawą kultury organizacyjnej szkoły są założenia. Ich koncepcja wyznacza strukturę omawiania specyfiki kultury organizacyjnej dwóch typów szkół integracyjnych. Założenia te prezentuję w innej kolejności w odniesieniu do modelu Touhy, rozpo-

ne, 1994, IV, s. 10; B. Jałowiecki, S. Karpalski, Peryferia i pogranicza jako interdyscyplinarny obszar badawczy, [w:] Peryferia i pogranicza. O potrzebie różnorodności, red. B. Jałowiecki, S. Karpalski, Warszawa 2011, s. 21; Z. Gajdzica, Kategorie sukcesów w opiniach, s. 238-241.

22 I. Machaj, Pogranicze, [w:] Encyklopedia socjologii, red. H. Domański, W. Morawski, J. Mucha, M. Ofierska, J. Szacki, M. Ziółkowski, Warszawa 2000, s. 126. 
czynając od tych, które noszą znamiona założeń ontologicznych. Zdaję sobie sprawę z dyskusyjności takiego rozwiązania, wszak założenia w sprawie związków szkoły z otoczeniem odzwierciedlają oczekiwania społeczne wobec tej instytucji, co także uzasadnia ich prymarność wobec innych. W swoim wywodzie pragnę odwrócić sposób myślenia i w punkcie wyjścia ulokować ucznia $\mathrm{z}$ niepełnosprawnością, rozpatrując problematykę z punktu założeń osadzonych $\mathrm{w}$ wiedzy ugruntowanej $\mathrm{w}$ obszarze pedagogiki specjalnej, ze szczególnym uwzględnieniem sposobów postrzegania niepełnosprawności i ich pedagogicznych następstw. Hasłowe, w związku z tym uproszczone, zestawienie podstawowych założeń prezentuję $\mathrm{w}$ tabeli 1.

Tabela 1

Założenia kultury organizacyjnej dwóch koncepcji szkół integracyjnych

\begin{tabular}{|l|l|l|}
\hline \multicolumn{1}{|c|}{$\begin{array}{c}\text { Założenia kultury } \\
\text { organizacyjnej }\end{array}$} & \multicolumn{1}{c|}{\begin{tabular}{c}
\multicolumn{1}{c|}{ Kultura } \\
szkoły korygującej
\end{tabular}} & \multicolumn{1}{c|}{$\begin{array}{c}\text { Kultura } \\
\text { szkoły kompensującej }\end{array}$} \\
\hline Natury ludzkiej & $\begin{array}{l}\text { niepełnosprawność jako } \\
\text { uszkodzenie, zaburzenie } \\
\text { funkcjonalne }\end{array}$ & $\begin{array}{l}\text { niepełnosprawność jako } \\
\text { utrudnienie w realizowaniu } \\
\text { zadań rozwojowych i wy- } \\
\text { pełnianiu ról ucznia i kolegi }\end{array}$ \\
\hline Prawdy i czasu & $\begin{array}{l}\text { obiektywność kryteriów } \\
\text { niepełnosprawności, orien- } \\
\text { tacja na przeszłość i teraź- } \\
\text { niejszość }\end{array}$ & $\begin{array}{l}\text { relatywność kryteriów nie- } \\
\text { pełnosprawności, orientacja } \\
\text { na teraźniejszość } \\
\text { i przyszłość }\end{array}$ \\
\hline $\begin{array}{l}\text { Związków między } \\
\text { ludźmi }\end{array}$ & $\begin{array}{l}\text { relacje z przewagą hierar- } \\
\text { chicznych }\end{array}$ & $\begin{array}{l}\text { przeważające relacje syme- } \\
\text { tryczne }\end{array}$ \\
\hline $\begin{array}{l}\text { Natury ludzkich } \\
\text { działań }\end{array}$ & $\begin{array}{l}\text { w odniesieniu do uczniów } \\
\text { z niepełnosprawnością } \\
\text { dominacja celów i procedur } \\
\text { terapeutycznych (korygują- } \\
\text { cych) }\end{array}$ & $\begin{array}{l}\text { w odniesieniu do uczniów } \\
\text { z niepełnosprawnością } \\
\text { dominacja celów i procedur } \\
\text { edukacyjnych }\end{array}$ \\
\hline $\begin{array}{l}\text { Związków szkoły } \\
\text { z otoczeniem }\end{array}$ & $\begin{array}{l}\text { orientacja na związki } \\
\text { z instytucjami rehabilitują- } \\
\text { cymi, organizacjami działa- } \\
\text { jącymi na rzecz ON }\end{array}$ & $\begin{array}{l}\text { orientacje na związki } \\
\text { z różnymi instytucjami } \\
\text { o charakterze kulturowym, } \\
\text { edukującym, rehabilitują- } \\
\text { cym }\end{array}$ \\
\hline
\end{tabular}

Źródło: opracowanie własne.

Kultura szkoły określonej mianem korygującej wpisuje się w swoich założeniach w pierwszy typ pogranicza. Kreują go wartości i tradycje różnych tożsamości i profili mentalnych występujących obok siebie. Ich przenikanie

${ }^{23}$ D. Tuohy, Dusza szkoty, s. 27-36. 
jest ograniczone ze względu na kultywowanie odrębności, akcentowanie różnic wzmacnianych stereotypami. Podstawą tego założenia jest postrzeganie niepełnosprawności jako problemu ulokowanego w obiektywnej perspektywie ograniczeń fizjologicznych i ukonstytuowanych na nich zaburzeń funkcjonalnych. Założenie to $\mathrm{z}$ natury zakorzenione jest $\mathrm{w}$ temporalnej orientacji na przeszłość, która wyznacza obecny stan. Specjalne potrzeby edukacyjne definiowane są jako następstwa ograniczeń funkcjonalnych, a działalność edukacyjna podporządkowana jest hierarchicznie procesom terapii. To zaś wyznacza niesymetryczne relacje między nauczycielami a terapeutami i pedagogami specjalnymi współorganizującymi proces kształcenia, który przyjmuje pozycję dominującą. Misja szkoły uwydatnia realizację celów rehabilitacyjnych i zbliża w sposób naturalny placówkę do poszukiwania wsparcia $\mathrm{w}$ instytucjach medycznych, rehabilitujących. Założenia te sprzyjają budowaniu opozycji między praktykami podejmowanymi w związku i na rzecz uczniów z orzeczoną potrzebą kształcenia specjalnego oraz pozostałych uczniów, akcentując różnice i faworyzując działania korygujące. To zaś w praktyce wydatnie utrudnia integrację normatywną, funkcjonalną oraz komunikatywną. Sprzyja natomiast indywidualizacji i zaspokajaniu specyficznych potrzeb uczniów z niepełnosprawnością.

Kultura szkoły kompensującej lokuje się w drugim typie pogranicza, opartym na wzajemnym przenikaniu się tradycji, wartości, norm, założeń. Ukierunkowana jest zatem na poszukiwanie własności wspólnych. Założenia konstytuują się na biopsychospołecznym modelu niepełnosprawności, akcentując jego kulturowy wymiar. To zaś sprzyja traktowaniu niepełnosprawności jako stanu relatywnego, definiowanego w aspekcie zróżnicowanych potrzeb i możliwości, ujawnianego $\mathrm{w}$ realizacji konkretnych zadań oraz $\mathrm{w}$ interakcjach. Założenia te zakorzenione są $\mathrm{w}$ temporalnej orientacji na teraźniejszość (okoliczności, które ujawniają i/lub generują bariery i ograniczenia) oraz perspektywę przyszłości. Specjalne potrzeby edukacyjne definiowane są $\mathrm{w}$ aspekcie określonych działań podejmowanych w związku z rozwojem uczniów. Nie deprecjonują one działań korekcyjnych, ale sprzyjają ich postrzeganiu jako narzędzia do realizacji zadań edukacyjnych. Relacje oparte są na symetrycznych interakcjach między nauczycielami a terapeutami i nauczycielami współorganizującymi proces edukacji. Misja szkoły ujawnia się przede wszystkim w realizacji celów edukacyjnych, sprzyja nawiązywaniu relacji z różnymi instytucjami, organizacjami ukierunkowanymi na realizację i wspieranie zadań kulturotwórczych, edukacyjnych, rehabilitacyjnych. Założenia te sprzyjają kreowaniu wspólnoty wszystkich uczniów w szkole, zacieraniu się różnic między założeniami edukacji osadzonej $\mathrm{w}$ tradycji szkoły specjalnej oraz ogólnodostępnej. 
W wyniku takich założeń wiele celów kierowanych jest i realizowanych wspólnie, co sprzyja autentycznej integracji funkcjonalnej, normatywnej oraz kulturowej.

\section{Zakończenie}

Dwa wskazane typy (nieco umownie określane jako korygujący i kompensujący) stanowią namiastkę koncepcji kultur organizacyjnych szkół integracyjnych. $W$ praktyce zapewne nie występują (albo występują bardzo rzadko) one w czystej postaci. Każda placówka tworzy unikatowy efekt pogranicza jako swoistą jakość ${ }^{24}$. W zależności od przyjętej perspektywy można rozpatrywać go jako następstwo oczekiwań społecznych, ale także czynnik kreujący procesy i stany w szkole oraz jej właściwości. Przestrzeń pogranicza szkoły integracyjnej tworzy specyficzne możliwości zaspokajania potrzeb uczniów i nauczycieli. W tym kontekście jako naturalne jawi się pytanie o wpływ tej kultury na rozwój wszystkich uczniów. Zderzanie się i współistnienie dwóch odmiennych kultur zwykle prowadzi do wygenerowania jednej z nich jako przeważającej. Tak jest również w szkole integracyjnej. Możliwe jest zatem zdominowanie założeń stanowiących podstawę organizacji szkoły przez kulturę niepełnosprawności; wówczas szkoła może (aczkolwiek nie musi) lepiej spełniać funkcje opiekuńcze i terapeutyczne wobec uczniów z orzeczoną potrzebą kształcenia specjalnego, ale traci cechy środowiska, które ją otocza. To zaś pozostaje w sprzeczności z ideą integracji edukacyjnej ukierunkowanej na tworzenie warunków możliwie pełnego rozwoju, zbliżonych do tych, jakie panują poza murami szkoły, gdzie dominuje kultura pełnosprawności.

Przedstawione namiastki koncepcji kultury organizacyjnej szkoły integracyjnej traktuję jako element teorii kształcenia integracyjnego, a zarazem przyczynek do jej rozszerzania o wskazane w tekście zagadnienia, które, w moim przekonaniu, warte są głębszego rozmysłu i eksploracji badawczej.

\section{BIBLIOGRAFIA}

Adrjan B., Kultura szkoty. W poszukiwaniu nieuchwytnego, Oficyna Wydawnicza Impuls, Kraków 2011.

Babiński G., Pogranicze etniczne, pogranicze kulturowe, peryferie. Szkic wstępny problematyki, Pogranicze. Studia Społeczne, 1994, IV.

${ }^{24}$ G. Babiński, Pogranicze etniczne, s. 10. 
Bełza M., Inny/Obcy (uczeń niepetnosprawny) jako podmiot "folkloru” szkolnego, Problemy Edukacji, Rehabilitacji i Socjalizacji Osób Niepełnosprawnych, 2016, 23.

Bruner J., Kultura edukacji, Wydawnictwo Universitas, Kraków 2010.

Burszta W.J., Antropologia kultury. Tematy, teorie, interpretacje, Wydawnictwo Zysk i S-ka, Poznań 1998.

Chomczyńska-Rubacha M., Szkolne środowisko uczenia się, [w:] Pedagogika, t. 2, red. Z. Kwieciński, B. Śliwerski, Wydawnictwo Naukowe PWN, Warszawa 2006.

Czerepaniak-Walczak M., Kultura szkoły - o jej złożoności i wielowymiarowości, Pedagogika Społeczna, 2015, 3(57).

Gajdzica Z., Kategorie sukcesów w opiniach nauczycieli klas integracyjnych jako przyczynek do poszukiwania koncepcji edukacji integracyjnej, Oficyna Wydawnicza Impuls, Kraków 2013.

Gajdzica Z., Klasa integracyjna jako przystań pograniczy, Teraźniejszość-Człowiek-Edukacja, 2015,4 .

Hofstede G., Hofstede G.J., Minkov M., Kultury i organizacje, Polskie Wydawnictwo Ekonomiczne, Warszawa 2011.

Hofstede J., Kultura i organizacje. Zaprogramowanie umystu, Polskie Wydawnictwo Ekonomiczne, Warszawa 2000.

Jałowiecki B., Karpalski S., Peryferia i pogranicza jako interdyscyplinarny obszar badawczy, [w:] Peryferia i pogranicza. O potrzebie różnorodności, red. B. Jałowiecki, S. Karpalski, Wydawnictwo Naukowe Scholar, Warszawa 2011.

Kantor R., Kultura pogranicza jako problem etnograficzny, [w:] Zderzenia i przenikania kultur na pograniczach, red. Z. Jasiński, J. Korbel, WSP, Opole 1989.

Kostera M., Antropologia organizacji. Metodologia badań terenowych, Wydawnictwo Naukowe PWN, Warszawa 2003.

Kron F.W., Pedagogika. Kluczowe zagadnienia. Pojęcia, procesy, modele, przekł. E. Cieślik, Gdańskie Wydawnictwo Psychologiczne, Sopot 2012.

Machaj I., Pogranicze, [w:] Encyklopedia socjologii, red. H. Domański, W. Morawski, J. Mucha, M. Ofierska, J. Szacki, M. Ziółkowski, Oficyna Naukowa, Warszawa 2000.

Schein E., Organization Culture and Leadership, Jossey Bass, San Francisco 1992.

Stoner J.A.F., Freeman R.E., Gilbert D.R., Kierowanie, przekł. A. Erlich, Polskie Wydawnictwo Ekonomiczne, Warszawa 2001.

Tuohy D., Dusza szkoły. O tym, co sprzyja zmianie i rozwojowi, przekł. K. Kruszewski, Wydawnictwo Naukowe PWN, Warszawa 2002.

Wojtowicz A., Istota i modele kultury organizacyjnej - przeglad koncepcji, Zeszyty Naukowe Małopolskiej Wyższej Szkoły Ekonomicznej w Tarnowie, 2004, 5. 